\title{
Home oxygen status and rehospitalisation and primary care requirements of infants with chronic lung disease
}

\author{
A Greenough, J Alexander, S Burgess, P A J Chetcuti, S Cox, W Lenney, F Turnbull, \\ N J Shaw, A Woods, J Boorman, S Coles, J Turner
}

See end of article for authors' affiliations

Correspondence to: Professor Greenough, Department of Child Health, King's College Hospital, London SE5 9RS, UK;

anne.greenough@kcl.ac.uk

Accepted 16 August 2001

\begin{abstract}
Objectives: To determine whether the rehospitalisation and primary care requirements of infants with chronic lung disease (CLD) during the first two years after birth were influenced by a requirement for supplementary oxygen after discharge from the neonatal intensive care unit.

Methods: Review of records from both the hospital and general practitioner.

Patients: 235 infants, median gestational age 27 (range 22-31) weeks, 88 of whom were receiving supplementary oxygen when discharged home.

Results: Overall, the infants required a median of 2 (range 0-20) admissions per patient, 8 (0-41) outpatient attendances, $13(0-76)$ contacts with the general practitioner, and $17(0-169)$ consultations with other primary healthcare professionals. The home oxygen patients required significantly more and longer admissions $(p<0.01)$ and more outpatient attendances $(p<0.05)$. The total cost of care per infant of the home oxygen group was greater $(p<0.001)$; this reflected higher costs for hospital stay $(p<0.01)$, total inpatient care $(p<0.01)$, and primary care drugs $(p<0.01)$.

Conclusion: Despite routine use of antenatal steroids and postnatal surfactant, certain patients with $C L D$, particularly those who receive home oxygen treatment, show high rates of utilisation of health service resources after discharge from the neonatal care unit.
\end{abstract}

$\mathrm{T}$ he incidence of chronic lung disease (CLD) following premature birth is increasing, mainly because of improved survival rates of infants born at very early gestation. It is important therefore to determine the continuing needs of affected infants to ensure appropriate allocation of health service resources. Many studies were performed before the routine use of antenatal steroids and postnatal surfactant and included relatively mature infants, and thus their results are not applicable to the present population of infants. In addition, the studies usually concentrated on rehospitalisation rates $^{1}$ and are likely to have underestimated health service utilisation after discharge from the neonatal intensive care unit. Infants with CLD are often suffering troublesome wheeze and cough at follow up, which may increase their outpatient attendances and primary care contacts. The most severely affected infants continue to require supplementary oxygen after term and after discharge home. Maintaining adequate oxygen saturation by giving supplementary oxygen, however, increases weight gain and reduces pulmonary artery pressure, airway resistance, and the frequency of intermittent hypoxaemic episodes. ${ }^{3}$ Thus it cannot be predicted whether infants requiring home oxygen will have higher rates of rehospitalisation and primary care contact than other infants with CLD, and no such comparison has been previously undertaken. The aims of this study were to assess healthcare use by infants with CLD during the first two years after birth and whether this was influenced by a continuing requirement for supplementary oxygen after discharge from the neonatal intensive care unit.

\section{METHODS}

A four centre study has previously been reported. ${ }^{4}$ The study sample consisted of neonates born at less than 32 weeks of gestational age who had been admitted during the first week after birth to one of four neonatal intensive care units between I July 1994 and I July 1997, subsequently developed CLD (defined as an oxygen dependency beyond 28 days after birth), and survived until discharge. A retrospective review was made of their care in the community and during any readmission after discharge from the neonatal intensive care unit until 2 years of age. In this paper, the data collected in the four centre study ${ }^{4}$ were reanalysed to assess whether health care utilisation of infants with CLD during the first two years after birth was influenced by a continuing requirement for supplementary oxygen after discharge from the neonatal intensive care unit. The study was approved by the local research ethics committee of each of the four hospitals.

From the neonatal admission records, the following data were retrieved: birth weight, use of antenatal steroids and postnatal surfactant, development of an air leak (pneumothorax/pulmonary interstitial emphysema) or patent ductus arteriosus (clinical diagnosis with or without echocardiographic confirmation), duration of ventilatory support and supplementary oxygen, and use of high frequency oscillation and/or nitric oxide. From the general practitioners' records, the following data were retrieved: the venue of all hospital readmissions, the number of general practitioner consultations, all medication prescribed, the use of home oxygen, the number of referrals to a health visitor or community paediatric nurse, and the use of community support services. For each hospital admission the following information was recorded: the diagnosis or symptoms leading to the admission, the duration of stay, whether the child was admitted to a paediatric ward, high dependency unit, or intensive care unit, days of supplementary oxygen and intravenous fluids, surgical or therapeutic procedures, and duration and frequency of all medication. Each infant's hospital records were examined to ascertain the number of outpatient attendances.

Costs were assessed over the two year period. The costs per bed per day were obtained from the four main hospitals in the study. The mean cost ( $£ 634$ per day for the high dependency

Abbreviations: CLD, chronic lung disease. 
Table 1 Basic details and neonatal intensive care unit outcome related to home oxygen status

\begin{tabular}{llll}
\hline & $\begin{array}{l}\text { All infants } \\
(\mathbf{n}=235)\end{array}$ & $\begin{array}{l}\text { Home oxygen } \\
(\mathbf{n}=88)\end{array}$ & $\begin{array}{l}\text { No home oxygen } \\
(\mathbf{n}=147)\end{array}$ \\
\hline Gestational age (weeks) & $27(22-31)$ & $27(23-31)$ & $27(22-31)$ \\
Birth weight (g) & $934(510-3000)$ & $927(510-2178)$ & $934(515-3000)$ \\
Antenatal corticosteroids & $86 \%$ & $95 \%$ & $82 \%$ \\
Postnatal surfactant & $87 \%$ & $93 \%$ & $84 \%$ \\
CPAP & $57 \%$ & $32 \%$ & $72 \%$ \\
IPPV & $97 \%$ & $97 \%$ & $97 \%$ \\
HFOV & $6 \%$ & $4 \%$ & $7 \%$ \\
NO & $3 \%$ & $3 \%$ & $4 \%$ \\
Airleak & $15 \%$ & $22 \%$ & $11 \%$ \\
Postnatal dexamethasone & $39 \%$ & $38 \%$ & $40 \%$ \\
\hline
\end{tabular}

Data are given as median (range) where applicable.

CPAP, Continuous positive airways pressure; IPPV, intermittent positive pressure ventilation; HFOV, high frequency oscillatory ventilation; NO, nitric oxide.

\begin{tabular}{llll} 
Table 2 & Hospital admissions related to home oxygen status & \\
\hline & $\begin{array}{l}\text { All infants } \\
(\mathrm{n}=235)\end{array}$ & $\begin{array}{l}\text { Home oxygen } \\
(\mathrm{n}=88)\end{array}$ & $\begin{array}{l}\text { No home oxygen } \\
(\mathrm{n}=147)\end{array}$ \\
\hline All admissions & $2(0-20)$ & $2(0-20)$ & $1(0-20)^{*}$ \\
$\quad$ Number per baby & $5(0-282)$ & $7(0-131)$ & $3(0-282)^{* *}$ \\
Duration per baby (days) & $1(0-20)$ & $2(0-19)$ & $1(0-20)^{* * *}$ \\
Admissions to paediatric wards & $3(0-239)$ & $4.5(0-86)$ & $2(0-239)^{* *}$ \\
$\quad \begin{array}{l}\text { Number per baby } \\
\text { Duration per baby (days) }\end{array}$ & & \\
\hline Data are given as median (range) & & \\
${ }^{*} p<0.05 ;{ }^{* *} p<0.01 ;{ }^{* * *} p<0.005$ compared with home oxygen group.
\end{tabular}

unit and $£ 1003$ per day for the intensive care unit) was used to calculate the cost of the stay. The cost of each admission to a high dependency unit or intensive care unit was calculated by multiplying the number of nights by the cost per bed per day, to which was added the cost of any surgical or therapeutic procedure. The cost of admission to a general paediatric ward was based on the data displayed on the NHS website (The New NHS 1999 Reference Costs). Drug costs were calculated from the British National Formulary prices and included all costs of domestic oxygen therapy. The cost of attendance as an outpatient was estimated assuming 15 minutes with a consultant paediatrician and using the mean of the outpatient cost of the four main hospitals. The cost of care by a general practitioner was estimated assuming an 8.4 minute consultation at the surgery ( $£ 18$ per consultation). The cost of a general practitioner's time was based on average net remuneration allowing for capital costs and overheads. The cost of a domiciliary visit by community staff was estimated assuming a 20 minute consultation. The cost of domiciliary visits for health visitors, paediatric nurses, and oxygen nurse specialists was based on average net remuneration for specialist nurses allowing for superannuation, national insurance, travel, and capital overheads ( $£ 27$ per visit). All visits to practice nurses or routine visits to health visitors, for example for immunisations, were not recorded, as these were considered to be normal costs for infants. The costs of care were summarised under six headings: primary care total, primary care respiratory related, primary care drugs, hospital drugs, hospital stay, and outpatient attendance.

\section{Analysis}

The patients were divided into two groups: the home oxygen group received supplementary oxygen when discharged home and the no home oxygen group did not. Differences between groups for continuous variables were assessed for statistical significance using a Kruskal-Wallis non-parametric analysis of variance, and differences between groups for categorical data were tested using either a $\chi^{2}$ or Fisher's exact test, as appropriate.

\section{Patients}

Screening of 1581 case records showed that 459 infants fulfilled the eligibility criteria. In 205 cases the detailed hospital $(n=200)$ or primary care $(n=5)$ records could not be retrieved, and in 19 cases written parental consent was not obtained. The study sample consisted of 235 infants with a median gestational age of 27 weeks (range 22-31) and birth weight of $934 \mathrm{~g}$ (510-3000). Eighty eight of the infants were discharged home in supplementary oxygen (table 1 ).

\section{RESULTS}

The 235 infants had a total of 560 hospital admissions, and the mean duration of stay per infant was 14.6 days. Seventy infants were never readmitted. The mean number of general paediatric ward admissions was two, with a mean duration of admission of 11.2 days. Twenty one children required admission to the intensive care unit, four on two occasions; the mean duration of stay was 0.8 days (table 2 ).

Eighty eight infants were discharged home in oxygen; the proportion of infants differed between the four centres $(8 \%$, $12 \%, 63 \%, 64 \%)$. The median duration that supplementary oxygen was required at home was five months (range 0.5-19.8). No infant who was discharged in air subsequently required supplementary oxygen at home. The home oxygen group differed significantly from the rest of the cohort in that a greater proportion had received antenatal steroids $(\mathrm{p}<0.05)$, more had received postnatal surfactant $(\mathrm{p}<0.05)$, a smaller proportion had been supported by continuous positive airways pressure $(\mathrm{p}<0.001)$, and a greater proportion developed an air leak $(p<0.05)$ (table 1$)$. The infants receiving oxygen at home had a total of 236 readmissions compared with 324 readmissions for those who did not receive oxygen at 
Table 3 Outpatient attendances and primary care contacts related to home oxygen status

\begin{tabular}{|c|c|c|c|}
\hline & All infants & Home oxygen & No home oxygen \\
\hline Outpatient attendances & $8(0-41)$ & $10(1-27)$ & $8(0-41)^{*}$ \\
\hline Contacts with general practitioner & $13(0-76)$ & $13(0-56)$ & $13(0-76)$ \\
\hline Community care contacts & $17(0-169)$ & $14(0-69)$ & $18(1-169)$ \\
\hline Consultations for respiratory illness & $6(0-48)$ & $6(0-28)$ & $5(0-48)$ \\
\hline
\end{tabular}

Table 4 Cost of care $(£)$ related to home oxygen status

\begin{tabular}{llll}
\hline & Total $(\mathrm{n}=235)$ & Home oxygen $(\mathrm{n}=88)$ & No home oxygen $(\mathrm{n}=147)$ \\
\hline Hospital stay & $3405(1264)(0-73931)$ & $4061(2245)(0-73931)$ & $3013(1156)(0-54470)^{*}$ \\
Hospital drugs & $92(9)(0-2235)$ & $107(19)(0-2235)$ & $84(5)(0-1978)$ \\
Total inpatient & $3498(1283)(0-74252)$ & $4168(2312)(0-74252)$ & $3096(1156)(0-56448)^{*}$ \\
Outpatient & $1071(899)(0-8701)$ & $1133(968)(114-8701)$ & $1034(864)(0-4616)$ \\
Primary care respiratory related & $152(126)(0-972)$ & $155(135)(0-729)$ & $150(117)(0-972)$ \\
Primary care drugs & $414(126)(0-2890)$ & $946(815)(105-2890)$ & $95(43)(0-1423)^{*}$ \\
Primary care total & $454(324)(0-4374)$ & $373(279)(0-1755)$ & $503(360)(18-4374)$ \\
Total & $5600(3261)(95-85831)$ & $6802(4824)(896-85831)$ & $4881(2539)(95-58444)^{* *}$ \\
\hline
\end{tabular}

Data are given as mean (median) (range).

${ }^{*} \mathrm{p}<0.01 ;{ }^{* *} \mathrm{p}<0.001$ compared with home oxygen group.

home. Eighteen $(20.5 \%)$ in the home oxygen group and 52 $(35.4 \%)$ in the no home oxygen group were never readmitted $(\mathrm{p}<0.06)$. Both the numbers and duration of admission to hospital and the general paediatric wards were significantly greater in the home oxygen group (table 2). There were 14 admissions ( 12 patients) to the paediatric intensive care unit in the home oxygen group and 11 (nine patients) in the no home oxygen group (NS). The duration of stay per patient also did not differ significantly between the two groups, being a median of 0 days ( $0-38)$ in the home oxygen group and 0 days $(0-23)$ in the no home oxygen group. The home oxygen group required more outpatient attendances $(p<0.05)$ (table 3$)$. The total cost of care was higher in the home oxygen group $(p<0.001)$, the costs being greater for hospital stay $(\mathrm{p}<0.01)$, total inpatient care $(\mathrm{p}<0.01)$, and primary care drugs $(\mathrm{p}<0.01)$ (table 4$)$.

\section{DISCUSSION}

We have shown that infants with CLD who need supplementary oxygen at home require more frequent and longer readmissions than those who do not. This means that the total cost of their care during the two year period was about $40 \%$ greater. The infants studied were primarily cared for in four centres. They were identified retrospectively and thus no attempt could be made to standardise the criteria for use of home oxygen treatment between the centres. There is, however, controversy as to the most appropriate oxygen saturation level at which to maintain infants with $\mathrm{CLD}^{,-7}$ and, as a consequence, the use of home oxygen treatment varies between institutions, as indicated by our data. We feel therefore that our sample of infants using oxygen at home is representative, and we emphasise that our aim was to compare morbidity of infants who were and were not discharged home with supplementary oxygen.

Previous studies have shown that up to $50 \%$ of patients with CLD require readmission in the first year after birth and $20-37 \%$ in the second year. ${ }^{8-13}$ Some $70 \%$ of the present sample required at least one readmission during the first two years. The mean number of readmissions (2.4) per patient was lower than previously reported (five). ${ }^{13}$ CLD has been variously defined, including oxygen dependency beyond 28 days or 36 weeks of postconceptional age. ${ }^{14}$ We used the former definition as it has often been used in clinical trials, ${ }^{15}{ }^{16}$ and, in the

\section{Key message}

Infants with CLD who require supplementary oxygen at home have high rates of utilisation of health service resources after discharge from the neonatal care unit

present population of prematurely born infants, is a sensitive and specific predictor of chronic respiratory morbidity. ${ }^{17}$ Earlier reports used the same definition, implying that disease definition does not account for the differences in the number of readmissions. Our sample was identified retrospectively; however, not only were hospital records examined to identify readmissions but the general practitioners' case notes were also scrutinised. Many previous studies that examined readmission rates in infants with CLD were carried out in the 1980s. It is possible that routine use of both antenatal steroids and postnatal surfactant may have impacted favourably on the number of readmissions required by infants with CLD.

In a prospective study, ${ }^{19} 12$ of 21 infants were readmitted during a mean of 6.9 months while needing home oxygen treatment. About $80 \%$ of the infants needing oxygen at home in our study required at least one readmission in the first two years after birth. The proportion of the rest of the cohort requiring admission was not dissimilar (65\%), but that group spent significantly shorter periods in hospital (table 2). In addition, although the home oxygen group did not have more primary care contacts, outpatient attendances were more frequent. These differences may reflect the fact that, in the United Kingdom, consultant supervision of home oxygen programmes is hospital based.

One third of our infants with CLD were discharged home in supplementary oxygen. Increasing survival rates of very immature infants may result in a greater proportion of infants with CLD being dependent on home oxygen in the future. The greater healthcare utilisation and associated costs of oxygen supplementation at home shown here have important implications for the planning of health service resource allocation. Our data emphasise the urgency of identifying an effective and safe method of preventing CLD. 


\section{ACKNOWLEDGEMENTS}

The research nurses were funded by Abbott Laboratories. We are grateful to Mr Mark Elsley for assistance with data analysis and Ms Sue Williams for secretarial assistance.

\section{Authors' affiliations}

A Greenough, S Cox, Department of Child Health, King's College Hospital, London, UK

J Alexander, W Lenney, F Turnbull, North Staffordshire Hospital, Stoke on Trent, UK

S Burgess, PAJ Chetcuti, Department of Neonatal Medicine, Leeds General Infirmary, Leeds, UK

NJ Shaw, A Woods, Liverpool Women's Hospital, Liverpool, UK

J Boorman, S Coles, Abbott Laboratories Ltd, Maidenhead, Berks, UK

J Turner, Therapeutic Management, Crowthorne, Surrey, UK

\section{REFERENCES}

1 Furman L, Baley J, Borawski-Clark E, et al. Hospitalization as a measure of morbidity among very low birth weight infants with chronic lung disease. J Pediatr 1996;128:447-52.

2 Giffin F, Greenough A, Yuksel B. Does the duration of oxygen dependence after birth influence subsequent respiratory morbidity? Eur J Pediatr 1994;153:34-7.

3 Poets CF. When do infants need additional inspired oxygen? A review of the current literature. Pediatr Pulmonol 1998;26:424-8.

4 Greenough A, Cox S, Alexander J, et al. Health care utilisation of CLD infants related to hospitalisation for RSV infection. Arch Dis Child 2001;85:463-8.

5 Greenough A. Commentary: breathing patterns, oxygen and carbon dioxide levels during infancy. Acta Paediatr 2000;89:1275-83.

6 Poets CF, Samuels MP, Southall DP. Hypoxaemia in infants with bronchopulmonary dysplasia. Pediatrics 1993;92:186-7.
7 Groothuis JR, Rosenberg AA. Home oxygen promotes weight gain in infants with bronchopulmonary dysplasia. American Journal of Diseases in Children 1987;141:992-5.

8 Mayes $L$, Perkett E, Stahlman MT. Severe bronchopulmonary dysplasia: a retrospective review. Acta Paediatr Scand 1983:72:225-8.

9 Koops BL, Abman SH, Accurso FJ. Outpatient management and follow-up of bronchopulmonary dysplasia. Clin Perinatol 1984;11:101-22.

10 O'Brodovich HM, Mellins RB. Bronchopulmonary dysplasia. Unresolved neonatal acute lung injury. Am Rev Respir Dis 1985;132:694-709.

11 Bancalari E, Gerhardt T. Bronchopulmonary dysplasia. Pediatr Clin N Am 1986:33:1-23.

12 Markestad T, Fitzhardinge PM. Growth and development in children recovering from bronchopulmonary dysplasia. J Pediatr 1981;98:597-602.

13 Yu VYH, Orgill AA, Lim SB, et al. Growth and development of very low birthweight infants recovering from bronchopulmonary dysplasia. Arch Dis Child 1983:58:791-4.

14 Shennan AT, Dunn MS, Ohlsson A, et al. Abnormal pulmonary outcomes in premature infants: prediction from oxygen requirement in the neonatal period. Pediatrics 1988;82:527-32

15 Anonymous. Palivizumab, a humanized respiratory syncytial virus monoclonal antibody, reduces hospitalization from respiratory syncytial virus infection in high-risk infants. The IMpact-RSV Study Group. Pediatrics 1998;102:531-7.

16 The PREVENT study group. Reduction of respiratory syncytial virus hospitalization among premature infants and infants with bronchopulmonary dysplasia using respiratory syncytial virus immune globulin prophylaxis. Pediatrics 1997:99:93-9.

17 Kinali M, Greenough A, Dimitriou G, et al. Chronic respiratory morbidity following premature delivery: prediction of prolonged respiratory support requirement. Eur J Pediatr 1999;158:493-6

18 Palta M, Sadek M, Barnet JH, et al. Evaluation of criteria for chronic lung disease in surviving very low birthweight infants. J Pediatr 1998:132:57-63.

19 Baraldi E, Carra S, Vencato F, et al. Home oxygen therapy in infants with bronchopulmonary dysplasia: a prospective study. Eur J Pediatr 1997; 156:878-82

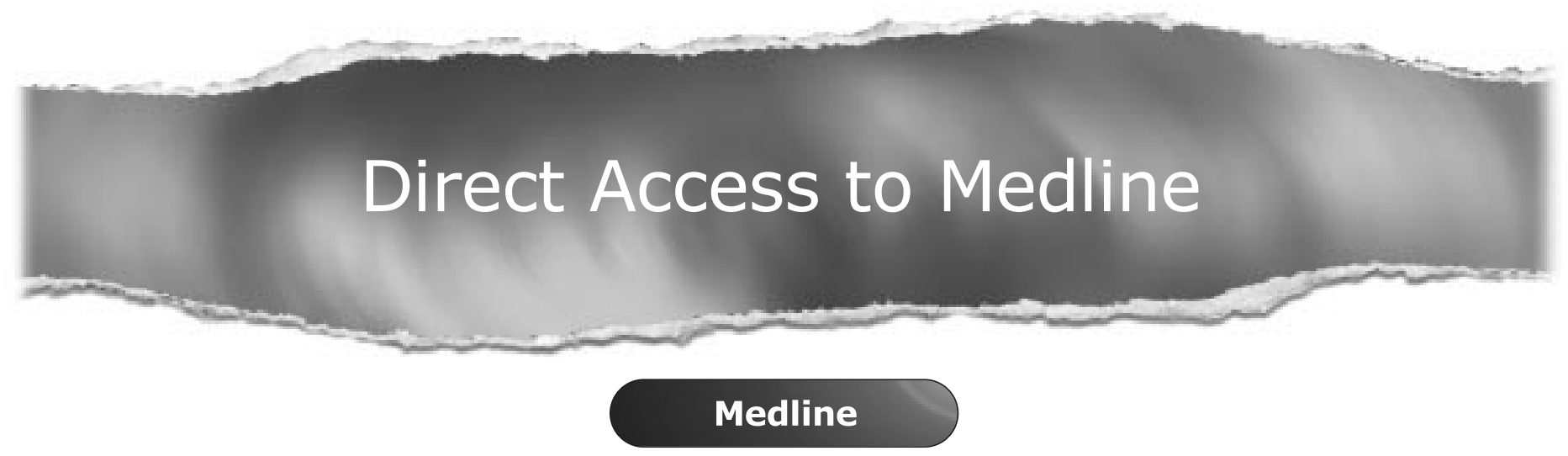

Link to Medline from the homepage and get straight into the National Library of Medicine's premier bibliographic database. Medline allows you to search across 9 million records of bibliographic citations and author abstracts from approximately 3,900 current biomedical journals.

www.archdischild.com 